\title{
A case study of an holistic approach to leachate and storm-water management developed at a municipal landfill site
}

\author{
I. Madon \\ Komunalno-stanovanjska družba Ajdovščina, Slovenia
}

\begin{abstract}
One of the basic conceptual approaches to water management at landfill sites is to hydrologically limit the generation of leachate during all stages of facility development in favor of producing larger amounts of non-polluted surface water run-off. However, there are some negative aspects to such an approach: 1) regulatory monitoring requirements are customarily not focused on the detection of potentially large amounts of contaminants which can be repeatedly released into the environment by means of storm water run-off; 2) subsequent to the required 30-year, post-closure monitoring and maintenance activities, common dry- or even wet-type landfills will in principle still pose a threat to the surrounding water environment; 3) a landfill is usually designed to function as an independent technological unit from the inception of the facility to the post- closure stage of its development. A different conceptual approach was undertaken at a pilot scale landfill complex in Ajdovščina, Slovenia, implementing landfill technology that combines the following interrelated elements to function together within a holistically designed system: 1) light waste compaction; 2) passive landfill aeration; 3) landfill bioreactor flushing; 4) landfill interior transient water storage and 5) inclusion of completed landfill sections into a common water catchment and recirculation area.

Keywords: flushing landfill, surface runoff, leachate recirculation, leachate treatment, sewage sludge management, semiaerobic landfill, waste management.
\end{abstract}

\section{Introduction}

State of the art municipal landfills may differ among themselves in many technological standpoints, however, they have some characteristics in common 
which collectively distinguish them from the earlier, much despised 'dump sites': they are categorically designed to be containment facilities effectively isolating buried waste from the surrounding environment: not only from the groundwater, but from the rainwater and air as well. In order to maximize utilization of such precious landfill airspace, exhaustive waste compaction also appears to be an indispensable part of the modern concept of landfilling. One of the major negative aspects of this concept is that the buried waste ends up being permanently stored in an unstabilized form posing a threat to the surrounding environment for an indefinite period of time. Even the best liner and leachate collection systems will ultimately fail. Therefore, such an approach cannot be considered to be compliant with the principles of a sustainable development.

At first it seems that the concept of landfilled waste isolation was never in collision with the concept of landfilled waste stabilization. However, it is a known fact that heavily compacted waste decomposes with difficulty, causing considerable problems to landfill operators applying any sort of wastestabilization technology (e.g. Reinhart and Townsend [1], Stegmann and Ritzkowski [2], Hettiarachchi [3]). The cost of such an approach appears to be very high too, sometimes easily overriding the benefits supposedly earned by rescuing impressive percentages of landfill airspace by performing heavy waste compaction. This is especially true in settings where land appears to be abundant and inexpensive.

When comparing wastes of otherwise equal characteristics, lightly compacted waste always stabilizes faster when compared to heavily compacted waste, produces leachate of better water-quality and generates less methane and odors (e.g. Kjeldsen and Christophersen [4], Komilis and Stegmann [5]. This property was/is systematically used at the Ajdovščina landfill site where a particular type of pump and treat aerobic flushing technology was implemented more than a decade ago (Madon [6-8]). A low density waste was/is achieved by distributing the waste deposited by transfer vehicles in layers a few meters thick (rather than thin ones) and by avoiding the use of a wheel compactor. In this way, the acquired density of landfilled waste does not exceed $300 \mathrm{~kg} / \mathrm{m}^{3}$, as opposed to more than the $700 \mathrm{~kg} / \mathrm{m}^{3}$ typically obtained in compacted landfills. Consequently, operating costs are very low, even when compared to Fukuoka type of semi-aerobic landfills (Chong et al. [9]).

\section{Case study site information}

Ajdovščina landfill operates as a pilot-scale research facility, performing above standard environmental monitoring activities, which is quite a unique feature for such a small site. Since the Ajdovščina concept of landfill site design, development, operation, phasing and intended post-closure use differs significantly from the standard ones, certain technical details which strictly refer to conventional landfill types (i.e., dry- or wet-type anaerobic landfills) do not comply well with the requirements imposed by the regulations. Fortunately, the European Landfill Directive, as well as Slovene regulations, indirectly allow the existence of non-conventional types of landfills, too, as the Appendix B included in the Annex to the Ordinance 2003/33/ES suggests. 


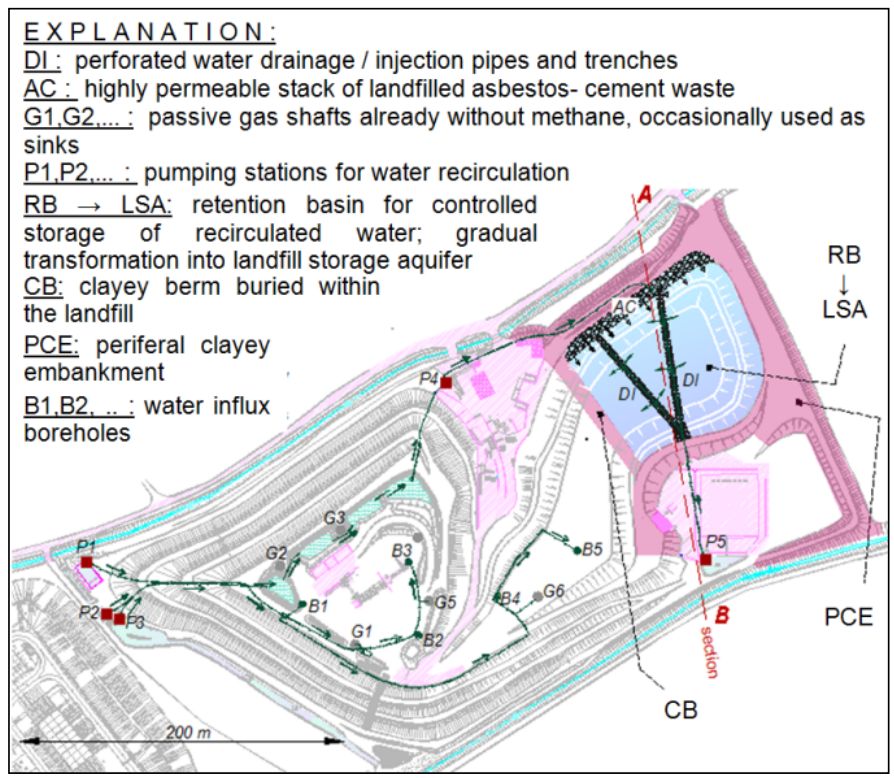

Figure 1: Situation of the landfill site with the emphasis on infrastructure implemented for purposes of transient storage of recirculated waters.

Actual landfill capacity: $\sim 650.000 \mathrm{~m}^{3} ; \sim 100.000 \mathrm{~m}^{3}$ of this airspace is occupied by mineral materials (buried clayey sanitary covers, etc.).

Total admission of waste to the site during the period 2010-2013: 12,000 tons/year. Soil and debris: additional $\sim 6.000 \mathrm{t} / \mathrm{yr}$.

Landfilled MSW and similar waste during the same period: $\sim 6.500$ tons/year.

Anaerobically pretreated dehydrated sewage sludge which was received, treated and disposed on site during the period 2010-2013: 2.000 tons/year.

Reclaimed waste fractions trucked away from the site 2010-2013: 2500 t/year.

Period of semi-legal dumping: 1980-2002.

Total surface area of the landfill complex: 7 ha.

Landfill footprint surface area: completed sections 4 ha, working face 1 ha.

Paved areas (reception area, reclamation site, compost platform): 1 ha.

Geology: fairly uniform clayey aquitard several meters thick, underlaid by more than a hundred meters of marly aquiclude. Terrain: flat.

Hydrogeology: No groundwater bodies exist in the influence area and beyond.

Precipitation and potential evaporation: $\sim 1.550 \mathrm{~mm} /$ year each.

Methane emissions: Less than $10 \%$ of biodegradable carbon placed in the landfill ends up into the atmosphere as methane emissions (flux chamber monitoring).

The land raising or area method of landfilling was applied, which is the disposal of waste by depositing on the land instead of into the land (Figs 2 and 3). This environmental setting provides: a) the largest possible surface area of landfill to 
be in contact with the atmosphere; b) the most reliable way to eliminate risks of contaminating the surrounding water bodies; c) the most reliable configuration to eliminate risks of external water inflows or intrusions to the site; and d) the independent landfill drainage system entirely driven by gravity.

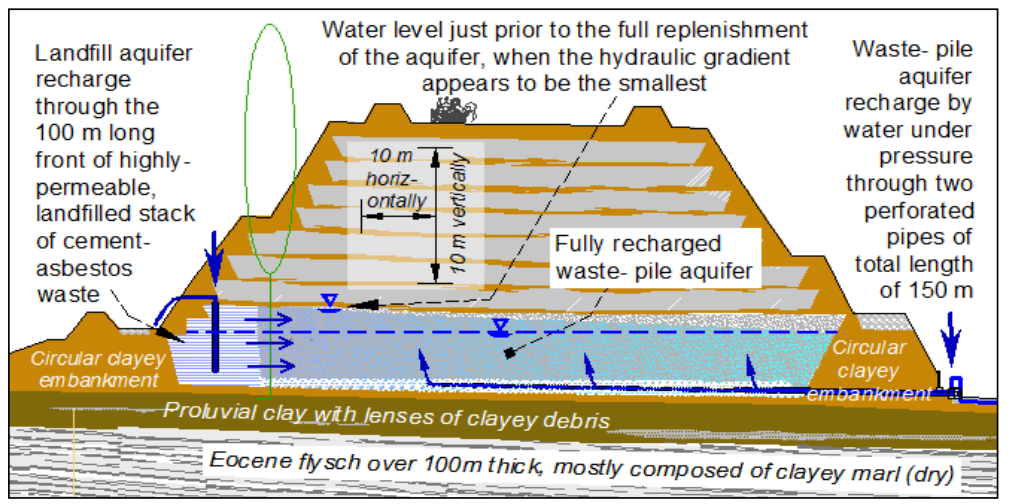

Figure 2: Demonstrative cross-section A-B through the third sector of the Ajdovščina landfill as it will appear after its completion. The bottom of the waste-pile structure is formed as a clayey bowl (former open air retention basin with poplar trees) for purposes of controllable storage of recirculated water.

The waste pile is sub-horizontally stratified in a way that a few meters thick, lightly compacted, fairly permeable layers of waste within the landfill alternate with up to half a meter thick lenses made up from clayey soils (buried sanitary covers) of low permeability. Engineered permeable blankets and trenches for water drainage and/or landfill gasses collection are not needed at all, since the buried layers of waste convey the fluids efficiently by themselves. Gaps scattered among the clayey lenses provide for sufficient mobility of waters and gasses in the vertical direction, too, the overall saturated water conductivity in a vertical direction being one decade order of magnitude lower than in the horizontal directions through the layers of waste.

\subsection{Implemented technological applications exploiting large surface areas of terraces and slopes of the completed landfill sections}

\subsubsection{Dehydrated sewage sludge storage, treatment and usage}

Solar drying requires space, but the operational costs are extremely low (e.g., WendeWolf [10]). Bench-roads placed all along the perimeter of the landfill (Fig. 1) are used for the purpose of transporting and spreading the dehydrated, anaerobically pre-treated sludges over the already mowed landfill slopes during the hot, sunny summer days using lateral manure spreader. Part of the top plateau is used for storing the sludge generated during the autumn, winter and spring months. The approach employed here is simple: when a thin layer of dehydrated 
solid sludge is subject to intense summer-season solar radiation the processes of drying, sanitizing and dry matter dissipation all occur simultaneously. $1000 \mathrm{t} / \mathrm{ha}$ of pretreated sewage sludge with $25 \%$ dry matter is applied over the landfill slopes each year. These activities can be considered to be part of the landscaping and landfill cover maintenance operations already required by the regulations. The system works fine from a water-quality point of view, since the infrastructure for the interception, collection and treatment of storm water run-off is part of the system.

\subsubsection{Outdoor mechanical processing and sorting of waste}

The plant was installed on the top terrace (Fig. 1) eight years ago and the only serious problem appeared to be windblown litter. Differential settlements underneath the pad foundations bearing steel frame construction are leveled easily once per two years by adding steel plates under the uprights as appropriate.

\subsection{The hydrological research performed on-site}

In order to acquire assessment values for coefficients of saturated hydraulic conductivity (' $\mathrm{k}_{\text {sat }}$ ') through the water- saturated layers of waste, pump-out and pump-in tests were performed as well as several slug tests. All of the obtained values were found to range between $1 \cdot 10^{-4} \mathrm{~m} / \mathrm{s}$ and $1 \cdot 10^{-5} \mathrm{~m} / \mathrm{s}$.

Infiltration tests through the compact clayey soil cover on the top of the landfill were performed in order to acquire the related ' $\mathrm{k}_{\mathrm{sat}}$ ' value, $\mathrm{k}_{\mathrm{sat}} \approx 6 \cdot 10^{-8} \mathrm{~m} / \mathrm{s}$.

An indirect test measuring streamflow through the dam blocking the ditch located next to the landfill was performed under steady- state conditions in order to acquire ' $\mathrm{k}_{\mathrm{sat}}$ ' value of permeable soil covering the landfill slopes. The temporary dam was namely constructed from the same lightly compacted clayey/humus soil which was also used for covering the slopes. $\mathrm{k}_{\text {sat }} \approx 4.4 \cdot 10^{-5} \mathrm{~m} / \mathrm{s}$.

Small-scale pilot tests were performed in order to evaluate the 'field moisture capacity' and 'drainable porosity' characteristic parameter values for noncompacted waste, i.e.: variously pretreated municipal solid wastes were: 1) placed into impermeable caisson having a volume of $130 \mathrm{~m}^{3}$; 2) saturated with water; and 3 ) dewatered. Measurement results are presented in Table 1. Water content values during different phases are expressed in mass \%, except for the 'storage capacity' row, where the data values are expressed also in vol. \%, presented in square brackets. Moisture content values related to MSW entering the site were acquired by performing separate measurements.

Evaporation tests were performed within a controlled water recycling system by spraying water over a slightly inclined paved surface having an area of $1000 \mathrm{~m}^{2}$ and measuring water losses as a function of time. It has been found that the water losses per $1 \mathrm{~m}^{2}$ of landfill surface area appear to be amplified by almost a factor of ' 2 ' when performing spraying in comparison to the calculated potential evapotranspiration value given by the on-site weather station utilizing meteorological data gathered during the same period of time. 
Table 1: Water contents (w.c.) within the waste.

\begin{tabular}{|c|c|c|c|}
\hline $\begin{array}{c}\text { MSW } \\
\text { pre-treatment }\end{array}$ & No treatment & Bag-cutting & Shredding \\
\hline w.c. $\downarrow$ & & & \\
\hline 1 & 32 & 34 & 29 \\
\hline 2 & 64 & 71 & 54 \\
\hline 3 & 45 & 49 & 43 \\
\hline 4 & 40 & 44 & 39 \\
\hline 5 & $24[20]$ & $27[37]$ & $15[31]$ \\
\hline $1 \rightarrow$ & \multicolumn{3}{|c|}{ Initial moisture content within the placed waste } \\
\hline $2 \rightarrow$ & \multicolumn{3}{|c|}{ After saturation with water } \\
\hline $3 \rightarrow$ & \multicolumn{3}{|c|}{$\begin{array}{c}\text { After dewatering the saturated zone } \\
\text { (just after water level fell down to zero) }\end{array}$} \\
\hline $4 \rightarrow$ & \multicolumn{3}{|c|}{ Field moisture capacity value (no more leaching) } \\
\hline $5 \rightarrow$ & \multicolumn{3}{|c|}{ Water storage capacity of waste (2)-(4) } \\
\hline
\end{tabular}

Column tests were carried out by leaching the pretreated solid sewage sludge. The percolate was forced to pass through the reasonably thick soil layer before leaching out of the column in order to be filtered thoroughly. It has been shown that heavy metals within the sludge do not tend to leach-out as soluble species in the effluent. The officially prescribed procedure for sewage sludge leachate does not yield this result because colloidal particles are not removed by filtration.

In order to demonstrate the effectiveness of a clayey barrier underneath the landfill in attenuating the subterranean transport of dissolved pollutants, monitoring was/is performed comparing the water quality parameters of samples taken from two boreholes located just three meters from one another. Clean water samples are taken at the aquitard/aquiclude interface and leachate samples from the saturated zone just above the bottom of the landfill (Fig. 3). It is confirmed that contaminant transport through the saturated clayey proluvium is a very slow process as described by the equation in Fig. 3.

By analyzing data from the pump-in and pump-out tests as well as from the practical experience performing water recirculation it was recognized, that noncompacted landfilled waste decidedly represents a multi-porous and multipermeable medium. It is opportune to distinguish the porosity of the landfilled waste on channel-like porosity (due to the existence of intertwined and interconnected net of voids within the buried layers of uncompacted waste) and matrix porosity (all other kinds of porosities which exist within the buried material). Channel-like porosity is the one which predominantly contributes to water conductivity through the layers of waste (e.g., Powrie [11]). Heavy compaction of waste reduces the volume and interconnection of channels, consequently, the resultant values of ' $\mathrm{k}_{\mathrm{sat}}$ ' in such landfills typically appear to be smaller than $1.10^{-6} \mathrm{~m} / \mathrm{s}$. 


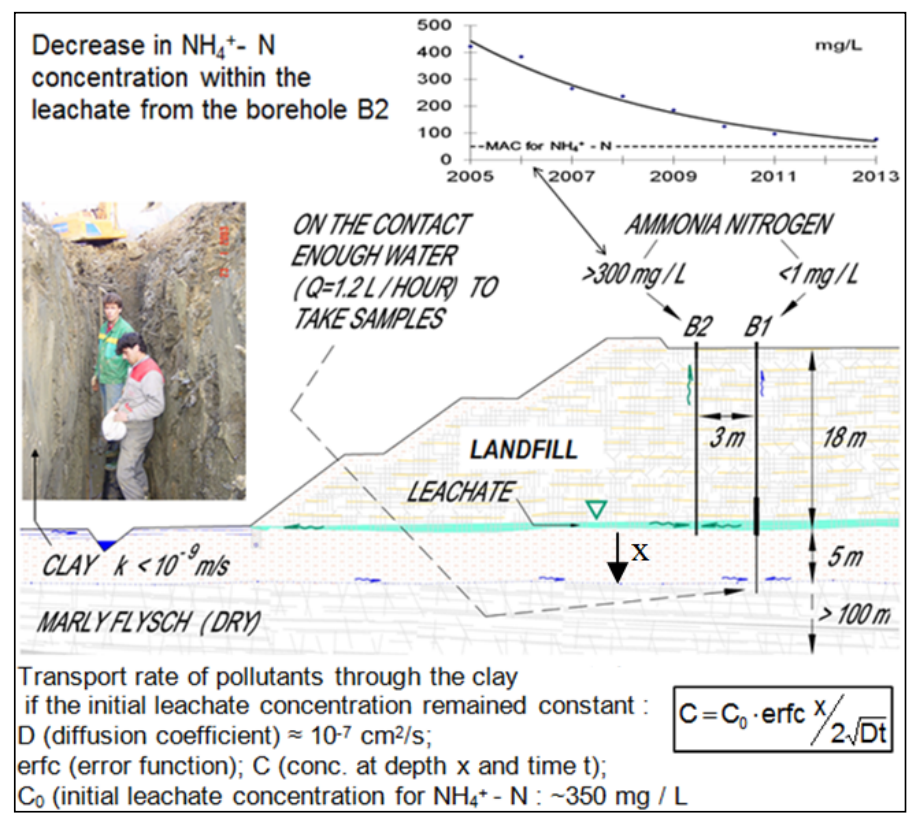

Figure 3: Cross section through the monitoring boreholes sunk into the landfill in order to perform research.

By analyzing the tests mentioned above it was discovered that interconnected channel-like porosity represents a very small part of the volume of the disposed of waste (less than 1\%). This sort of porosity therefore makes an insignificant contribution to the water storage capacity of the medium.

Assessment of the value of ' $\mathrm{k}_{\mathrm{sat}}$ ' for the matrix has been acquired by analyzing the rise of the water level after performing pumping test within the saturated zone on the bottom of the landfill. The coefficient of water conductivity value for the matrix appeared to be two decade orders of magnitude smaller than the one being pertinent to the interconnected network of voids.

\section{The implemented hydrologic applications}

\subsection{Hydrologic concept of the case study site as a whole}

Extensive, already capped areas of conventional landfills are utilized only for the purposes of landscaping and maintenance of the landfill gas collection - and surface runoff drainage - systems. Such solutions tend to be preferred by the regulations due to the unstable conditions within the interior of these landfills and the related long-lasting differential settlements taking place on the surface. Surface water runoff from these areas is usually directly conveyed to the environment. The hydrological goal is to generate as small a quantity of polluted surface runoff as possible. However, the quantity of pollutants permitted to be released yearly into 
the environment via effluent discharges can nevertheless be exceeded in certain environmental settings, such as: 1) when the permitted annual emission rates appear to be low for certain reasons (e.g., if the particular recipient demonstrates low streamflow rates and/or exhibits some special ecological status); and/or 2) if the quantity of polluted surface water produced is large due to groundwater intrusions and/or external surface water inflows to the site (canyon methodconstructed landfills are especially vulnerable); and/or 3) if reverse osmosis or other membrane filtration leachate treatment technology is employed in combination with recirculation of these highly polluted leachate concentrates back into the landfill (Fig. 4).

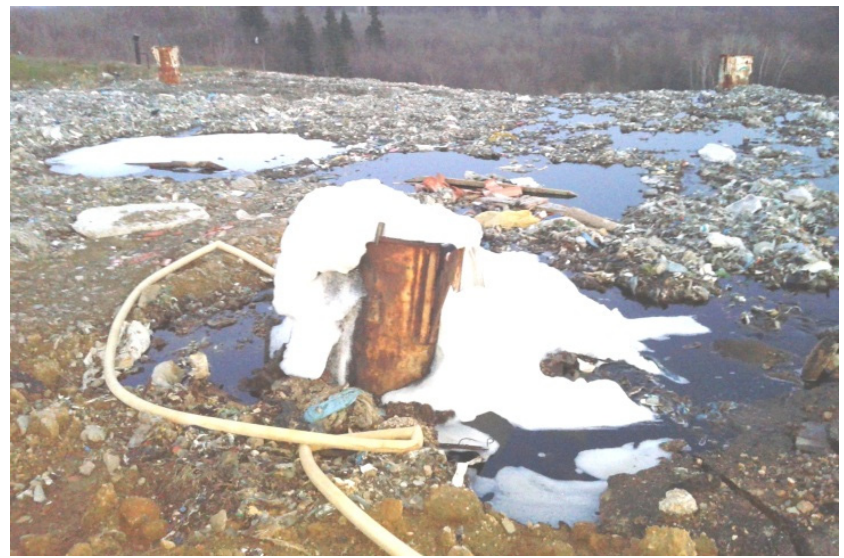

Figure 4: Display of the failed effort to recirculate reverse-osmosis-derived leachate concentrate back to the landfill through the passive gas shaft. Heavily compacted waste can become saturated/clogged quickly.

On the other hand, waste buried within the flushing bioreactor landfill (Reinhart [12]) stabilises quickly. The low-density type of flushing landfill also provides the opportunity for large quantities of waters to be transiently stored within the landfill interior (Madon [8]). There are no reliable hazards or obstacles which would suggest that the completed landfill surface areas on such sites should not be utilized for waste management related purposes.

All the wastewaters which are generated within the site boundaries (leachate that seeps out from the landfill, overflow that comes from the outdoor compost facility, run-off from the paved areas, run-off originating from the greened surfaces of the closed parts of the landfill, wheel-washing-overflow, etc.) appear to be contaminated with compatible pollutants. All of them are caught into a common drain system and conveyed through the common pipes into a common collection tank. The intercepted polluted waters are recirculated back onto/into the landfill in order to be either stored (during high water conditions - Figs 2 and 5), evaporated/transpirated (during windy, sunny and low humidity days) or purified (which is a continuous activity). Water purification takes place within the 250 meters long, passive, multiphase sequential system, where water is conveyed by 
gravity, with the upstream units installed on the top terrace and landfill slopes of the completed landfill (Fig. 5). Water at the end of the purification line can be either recirculated again in one or another way or discharged into the recipient. An automatic water-quality monitoring station is installed just upstream of the discharge point, providing on-line data about the reference parameters values: ammonium and nitrate concentrations and effluent discharge. If ammonium MAC levels are not exceeded, all the other parameters appear to be well below the MAC's, too, as monitoring results collected during the course of many years have shown.

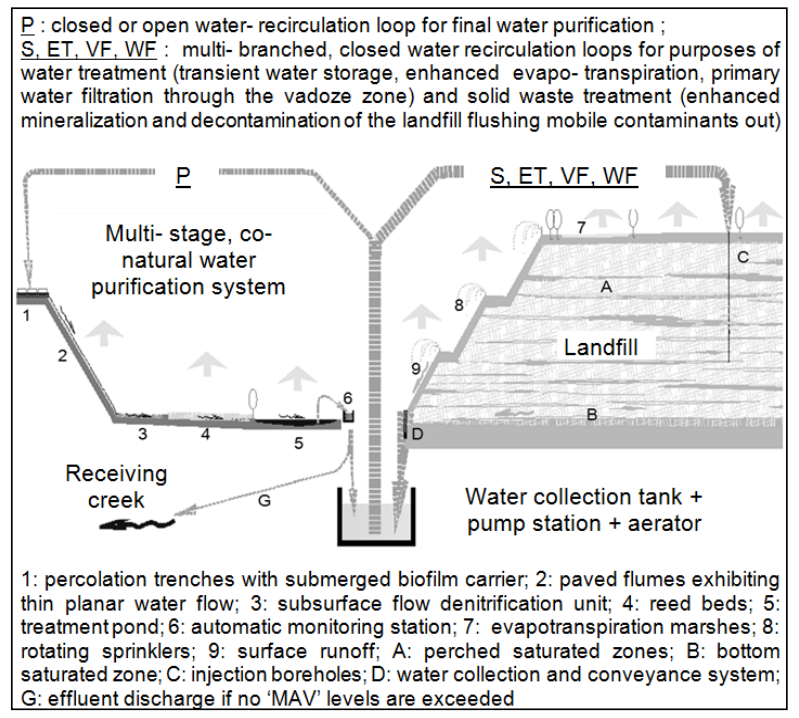

Figure 5: Schematic demonstration of the concept of water recirculation within several recirculation loops, applied on the Ajdovščina landfill site.

In the Ajdovščina case, the amount of aqueous pollutants released into the environment during heavy rain events is attenuated to the sufficient degree by means of: a) intercepting a fraction of the generated storm waters already in the upstream parts of the waste reclamation and disposal area, i.e. in small shafts and lagoons equipped with individual pumping stations, conveying water upstream into water retention structures, effectively cutting off peak flow rates downstream (Fig. 1); b) providing large water storage capacities; c) intercepting the already reduced storm water wave in the downstream collection tank recirculating the water into a few hundred meters long, gravitationally driven natural purification system before exiting the site as very lightly polluted water.

For purposes of accelerating water losses by evapotranspiration, water is recirculated into a gravitationally flowing system of successive shallow marshes, landscaped on the top of the plateau of the completed landfill (Figs 1 and 5) and/or to the system of rotating sprinklers spraying the water over a 2 hectare large surface area of the completed landfill slopes (Fig. 5). 


\subsection{Flushing mobile recalcitrant contaminants out of landfill}

High hydraulic transmissivity of the buried layers of waste allow for the recirculation of significantly larger water fluxes (some $40,000 \mathrm{~m}^{3} /$ year in the Ajdovščina case) when compared to anaerobic and even aerobic bioreactorlandfills (e.g., Bilgili et al. [13]) of comparable capacity, flushing the landfill vadose and saturated zones continually (Figs 1 and 5) rather than just filling up the pore volume up to the extent until field moisture capacity is attained. This results in fast and cheap stabilization, mineralization and decontamination of the landfill interior, nearly acquired during the first 5 years after the completion of a particular landfill section. Black colored sub-horizontal lenses of decimeter to meter thickness, which are mostly found at the bottom of the landfill, confirm the fact that colloids move quite easily through the network of voids and pores as well as that the stabilization rate is fast, since such lenses were discovered to exist in relatively young landfill sections. Black color namely derives from humic colloidal material which is flushed down from the upper landfill sections filling up the voids and pores within the oscillating fringe zone between the saturated and vadose zones. Fig. 6 shows an example of such material - the only not yet completely mineralized biodegradable matter which was found at the bottom of the landfill, together with some hard wood pieces.

Thick clayey liner below the land-raise method constructed landfill is basically all that is needed to protect hydrogeological environment during the active and closure landfill phases, when percolating leachate really exhibits relevant pollution potential, which is, however, rapidly fading (Fig. 3).

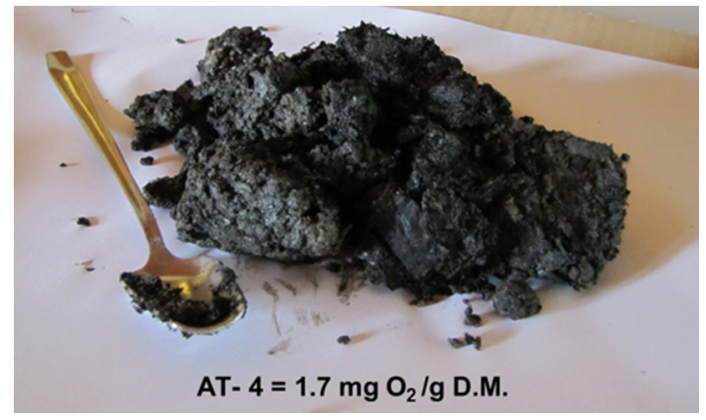

Figure 6: Sample of colloidal material derived from biodegradation processes accumulated at the bottom of the landfill. Respiration activity was also measured, as shown on the picture.

Leachate is constrained to slowly percolate above, around and through the horizontal layers and lenses of marly clayey soil derived from sanitary covers eventually dissolving calcite minerals there (Fig. 5). In this way leachate $\mathrm{pH}$ tends to equalise a little above the value of ' 7 '. A large mass of lime contained within the buried sanitary covers provides massive buffering capacity within the landfill interior preventing potential acidification of the leachate in the future, which consequently prevents the potential rise of heavy metals emissions, too. 
Relatively high oxidation-reduction potential (ORP) values are characteristic for semiaerobic landfill leachates when compared to anaerobic ones (values are always positive in the Ajdovščina case, usually higher than $100 \mathrm{mV}$ ). Consequently, only limited precipitation of iron oxides from the solution takes place. Clogging of the draining systems is almost non-existent resulting in less maintenance been needed.

\subsection{Transiently storing large quantities of water within the landfill}

A large fraction of the volume of pores and voids enclosed within the landfill where light compaction of waste is performed belongs to the drainable type of porosity, which is an almost nonexistent characteristic in heavily compacted landfills. This property allows for the large transient water storage capacity to be utilized for technological purposes performing water recirculation through the injection wells and used up gas shafts (Figs 1 and 5).

Since the hydraulic conductivities in vertical and horizontal directions within the landfill are different, the water can be dynamically stored there when performing intense recirculation (practice shows that up to $5 \%$ of the landfill airspace is possible to employ for the very purpose following prolonged periods of dry weather). Occassional seeps on the side slopes of the landfill which dewater the perched saturated zones are perceived as a welcome coincidence - by flowing on the surface the recirculating water purifies.

Uncontrollably high pore water pressure can not build up due to high drainability of refuse layers. Consequently, slope stability problems do not develop even if intense water recirculation is performed on a regular basis (Madon [7]).

An open air retention basin for controlled storage of large quantities of recirculated waters was built within a part of the landfill footprint, which was not occupied at the time, by raising a 4 meter high circular embankment of impermeable clayey material, with an area of 1 hectare, in order for it to be functional before and after becoming part of the landfill interior (Figs 1 and 2). Clayey bowl airspace was/is being filled gradually, for many years, separately from ordinary landfill operations on the active working face, primarily using selected, highly permeable waste fractions (e.g., asbestos cement waste, waste mattresses and other heavily recyclable bulky waste fractions) as well as shredded, stabilized MSW. The resulting hydraulic conductivity is expected to be high $\left(\mathrm{k} \approx 1.10^{-3} \mathrm{~m} / \mathrm{s}\right)$ which is an important consideration in order to recharge the landfill aquifer quickly during heavy rain conditions. The open air retention basin was/is gradually being transformed into an artificial landfill aquifer for controlled storage of recirculated water (some $\sim 25 \%$ of the aquifer airspace is available for being intermittently drained and replenished). The structure is equipped with intake and outlet works, which are used to regulate the inflow and outflow (Figs 1 and 2). The released water is then gravitationally conveyed to the collection tank as all the other water is.

The requirement to maintain less than $0.3 \mathrm{~m}$ of leachate water head on the liner is environmentally relevant for conventional landfills but is obviously irrelevant for the land-raise method constructed, lightly compacted, flushing semiaerobic 
landfill bioreactors, which are underlined by a thick layer of malleable clay. Besides if no body of ground water which is vulnerable to potential contaminantion lies below the landfill, this requirement does not make any sense.

\subsection{Treating the polluted waters within the landfill interior}

The landfill-site derived polluted water which is recirculated into the already stabilized sections of the landfill interior appears to be of lower quality when compared to the water on the exit of the landfill interior. Recirculated water is a mixture which also contains a fraction of water which is highly polluted, such as primary leachate seeping out from the active landfill section as well as eventual overflows originating from the compost and wheel cleaning areas. From a water quality point of view the system functions as a bio-filtering water treatment plant (Fig. 5). Of course, the amount of dissolved persistent contaminants exhibiting high water solubility (such as chloride ions) would gradually accumulate within the recirculating system rather than decline if no water is released into the environment.

\section{Environmental performance}

\subsection{Water quality of the primary leachate}

Leachate samples occasionally taken from the saturated zone at the bottom of the 20 meters high landfill section, completed nine years ago, demonstrate waterquality parameter values which do not exceed the MAC levels for an effluent which is permitted to be released in surface streams according to Slovene regulations, with the exception of ammonium concentration levels. However, after circa three years, this parameter will be abated below the prescribed MAC level, too, as can be deduced by data extrapolation (Fig. 3).

Leachate originating from the active section of the case study landfill is of better quality than that from conventional landfills as well, as table 2 shows.

Table 2: Water contents (w.c.) within the waste.

\begin{tabular}{|c|c|c|c|c|c|}
\hline & $\mathrm{NH}_{4}^{+}-\mathrm{N}$ & COD & $\mathrm{pH}$ & Toxicity (D. magna) & Heavy metals \\
\hline & $\mathrm{mg} / \mathrm{L}$ & $\mathrm{mg} \mathrm{O} / \mathrm{L}$ & 1 & $\mathrm{SD}_{\text {lday }}$ & $\mathrm{mg} / \mathrm{L}$ \\
\hline Ajdovščina & $50-160$ & $500-1500$ & $6.5-7.5$ & $3-4$ & $<1$ \\
\hline $\mathrm{C} 1$ & $100-400$ & $15,000-60,000$ & $3.5-6.5$ & & $>2$ \\
\hline $\mathrm{C} 2$ & $10-13,000$ & $1900-70,000$ & & & \\
\hline $\mathrm{C} 3$ & & & & $4-23$ & \\
\hline MAV & 50 & 300 & $6.5-9.0$ & 4 & 1.6 \\
\hline $\mathrm{C} 1 \rightarrow$ & \multicolumn{5}{|c|}{ Compilation from Kjeldsen et al. [14] } \\
\hline $\mathrm{C} 2 \rightarrow$ & \multicolumn{5}{|c|}{ Compilation from Renou et al. [15] } \\
\hline $\mathrm{C} 3 \rightarrow$ & \multicolumn{5}{|c|}{ Compilation from Slomczyinska [16] } \\
\hline
\end{tabular}




\subsection{Emissions of aqueous pollutants into the surface waters}

Official monitoring is performed at the effluent discharge point 4 times per year as required by Slovene regulations. Automated continuous monitoring is also performed. The results were always favorable. The Daphnia magna toxicity test value was always $\mathrm{SD}_{1 \text { day }}=1$. In fact, frogs inhabit water bodies in the purification line. The water also does not seem to be toxic to plants and algae. A dozen of 65 year old poplar trees are flooded with the recirculated water for eight months each year, and in the spring of each year these trees leaf out anew.

The mean annual low flow rate of the torrential stream flowing nearby to the landfill located within the reclamation ditch appears to be very low $(\sim 1 \mathrm{~L} / \mathrm{s})$. According to the calculation found from utilizing the officially prescribed formula, the allowed maximal annual amounts for certain pollutants would be exceeded easily, even if all of the annual measurement results demonstrated values below the level of the limit of detection and no water was ever released from the site during the low-flow conditions, which is of course an absurd situation. However, a river exhibiting three orders of magnitude bigger flow rates is less than 600 meters away and can also be considered to be the actual surface water recipient according to Slovene regulations. Such an interpretation would only not be allowed if the primary receiving stream was located in some natural preservation area.

Each year the emission rate of pollutants released from the study-case landfill site into the nearby surface waters appear to be fairly insignificant, which is true both in absolute and relative terms. For example: landfills are considered to be a relevant source of emissions of $\mathrm{AOX}$ (adsorbable organic halogens) into an aqueous environment. However, less than $2 \mathrm{~kg}$ of AOX is emitted into surface waters from the Ajdovščina landfill site annually. At least ten times more is released from the local WWTP located only $1 \mathrm{~km}$ away (monitoring AOX emissions from WWTP's is not even required).

\section{Conclusions}

The holistic approach to landfill operation and site development of the Ajdovščina case study demonstrates that streams of locally generated municipal waste and sludge can be mastered at the local level in an environmentally friendly, costeffective manner for the long term. The hydrological component of the practice includes these inter-related elements which function as part of a composite, sinergistically designed system: land-raise method of landfill construction, presence of a thick artificial and/or geological clayey barrier lying underneath the landfill, subhorizontal landfill stratification featuring permeable, lightly compacted layers of waste, integral polluted water management encompassing the site as a whole, water recirculation in multiple loops, integration of a upstreamlying retention basin and/or landfill water-storage aquifer into the system and fast stabilization and decontamination of the buried waste strata by applying pump and treat aerobic flushing technology. 
The case study presented here seems to be especially interesting for developing countries, where landfilling is still an important method of waste management and money for environmental protection is in scarce supply. However, such a site can be adequately managed only by environmentally educated personnel who are committed to the principles of sustainable development.

\section{References}

[1] Reinhart, D. R. and Townsend, T. G., Landfill Bioreactor Design and Operation. CRC Press: New York, 1998.

[2] Stegmann, R., Ritzkowski, M., (eds). Landfill aeration. CISA Publisher: Padova, Italy, 2002.

[3] Hettiarachchi P., Sustainable Landfills: The Future of Land Disposal of MSW. www.scribd.com/doc/9945961/sustainable-landfills

[4] Kjeldsen P., Christophersen M., Composition of Leachate from Old Landfills in Denmark. Waste Management \& Research, 19(3), pp. 249-256, 2001.

[5] Komilis D. P., Stegmann R., The Effect of Landfill Design and Operation Practices on Waste Degradation Behavior: a Review. Waste Management and Research, 17(1), pp. 20-26, 2000.

[6] Madon, I., Environmental, engineering and regulatory aspects of one formerly illegal municipal dumpsite. International conference on Groundwater in Geological Engineering, Bled, pp. 197-200, Slovenia, 2003.

[7] Madon I., Upgrading Small Municipal Dumpsite into an Environmentally Sustainable Landfill - Real Case Study. Internationl Geotechnological Conference 'ICWMEGGSD'07 - GzOv07'. Ljubljana, 2007. www.srdit.si/gzo07/14IMadon_FinalPaperGzO07.pdf

[8] Madon, I., Holistic, low-cost approach to solid waste and sewage sludge management on the local level, Ajdovščina case (in Slovene).

Part 1: Proceeding of 12th conf. Waste management - GzO'11, pp. 9-29.

Part 2: Proceeding of 14th conf. Waste management - GzO'13, pp. 1-18. Faculty of Natural Sciences and Engineering, Ljubljana.

[9] Chong, T.L., Matsufuji, Y., Hassan, M.N., Fukuoka method in developing countries: A Malaysia cost analysis. Waste Management 25, pp. 702-711, 2005.

[10] WendeWolf, http://www.wendewolf.com/klsbesch.php?lang=en

[11] Powrie, W., Landfill hydrogeology: impacts and challenges. www.geolsoc.org.uk

[12] Reinhart, D., Florida Bioreactor Landfill Demonstration Project: Lessons Learned; University of Central Florida. www.swananys.org/pdf/DReinhart.pdf

[13] Bilgili M., Demir A., Oczaya B., Quality and Quantity of Leachate in Aerobic Pilot-Scale Landfills. Environmental Management, 38(2), pp. 189196, 2006. 
[14] Kjeldsen P., Barlaz M., Rooker A. et al., Present and Long-Term Composition of MSW Landfill Leachate: A Review. Critical Reviews in Environmental Science and Technology, 32(4), pp. 297-336, 2002.

[15] Renou S., Givaudan JG, Poulain S., Dirassouyan F., Moulin P., Landfill Leachate Treatment, Review and Opportunity. J Hazard Mater. 11(3), pp. 468-493, 2008.

[16] Słomczyńska B., Słomczyński T., Physico-Chemical and Toxicological C haracteristics of Leachates from MSW Landfills. Polish Journal of Environmental Studies, 13(6), pp. 627-637, 2004. 